IZA DP No. 4308

Neighborhood Dynamics and the Housing Price Effects of Spatially Targeted Economic Development Policy

Douglas J. Krupka

Douglas S. Noonan

July 2009 


\title{
Neighborhood Dynamics and the Housing Price Effects of Spatially Targeted Economic Development Policy
}

\author{
Douglas J. Krupka \\ IZA \\ Douglas S. Noonan \\ Georgia Institute of Technology
}

Discussion Paper No. 4308

July 2009

IZA

P.O. Box 7240

53072 Bonn

Germany

Phone: +49-228-3894-0

Fax: +49-228-3894-180

E-mail: iza@iza.org

Any opinions expressed here are those of the author(s) and not those of IZA. Research published in this series may include views on policy, but the institute itself takes no institutional policy positions.

The Institute for the Study of Labor (IZA) in Bonn is a local and virtual international research center and a place of communication between science, politics and business. IZA is an independent nonprofit organization supported by Deutsche Post Foundation. The center is associated with the University of Bonn and offers a stimulating research environment through its international network, workshops and conferences, data service, project support, research visits and doctoral program. IZA engages in (i) original and internationally competitive research in all fields of labor economics, (ii) development of policy concepts, and (iii) dissemination of research results and concepts to the interested public.

IZA Discussion Papers often represent preliminary work and are circulated to encourage discussion. Citation of such a paper should account for its provisional character. A revised version may be available directly from the author. 


\section{ABSTRACT}

\section{Neighborhood Dynamics and the Housing Price Effects of Spatially Targeted Economic Development Policy*}

Neighborhoods are the result of a complicated interplay between residential choice, housing supply and the influences of the larger metropolitan system on its constituent parts. We model this interplay as a system of reduced-form equations in order to examine the effects of a generous spatially targeted economic development program (the federal Empowerment Zone program) on neighborhood characteristics, especially housing values. This system of equations approach allows us to compute direct effects of the policy intervention as well as the effects mediated through non-price channels such as changes in the housing stock or neighborhood demographics. In the process, we are able to shed light on the rich simultaneity among neighborhood characteristics, including housing prices.

JEL Classification: R0, R21, R31, R38, R58

Keywords: economic development, simultaneity

Corresponding author:

Douglas J. Krupka

IZA

P.O. Box 7240

D-53072 Bonn

Germany

E-mail: dkrupka@iza.org

\footnotetext{
* The authors would like to thank John Winters for valuable, reliable research assistance, Carolyn Fonseca, participants in sessions at the annual APPAM meetings in 2006, the AREUEA annual meetings in 2008 and participants in the Lincoln Institute of Land Policy "Impact of Public Policy on Land Values" workshop. This research benefited from the support of the Lincoln Institute of Land Policy. This document contains demographic data from Geolytics, Inc, East Brunswick, NJ.
} 


\section{INTRODUCTION}

Neighborhoods - on the one hand - are places. People live, work and commute through these places. They are centers of residents’ activities and social networks. From a more disinterested perspective, neighborhoods are a set of characteristics defined in space. Neighborhoods are characterized - at least to the econometrician - by factors such as population density, demographics, housing vintage and value. We are not the first to point out that these dimensions defining a neighborhood do not develop in isolation from one another. Neighborhoods are a result of the complicated interplay of these factors and the broader forces working on their metropolitan area and even the metropolitan system in general. This analysis addresses this rich simultaneity in the process of evaluating the effects of the federal Empowerment Zone (EZ) program: a generous spatially targeted economic development policy.

Because the EZ program is intended to improve neighborhoods along a variety of dimensions (McCarthy, 1998), an analysis of the program's effects on housing value is appropriate. Aside from the obvious connection between improved housing prices and the local property tax base, changes in housing prices reflect changes in local quality of life. Yet, home prices are a result of the complicated interplay among economic, demographic and housing market forces described above. The EZ program's effects will thus be seen in making neighborhoods more attractive along a variety of dimensions which then affect house values indirectly.

This paper looks at the effects of EZ program participation in a simultaneousequations setting which allows for the program’s multi-dimensional effects and interactions among the various neighborhood indicators. The specification also allows us 
to assess the value of the program's effects on neighborhood indicators other than home values, compute both direct and indirect effects of the program on home values and assess the importance of simultaneity in the setting of neighborhood housing prices and demographic and housing stock characteristics.

Identifying the causal effects of the program with both a difference-in-differences approach and through the use of exogenous instruments, we find that the program had substantial positive effects on neighborhood home values, but small and mostly offsetting indirect effects. The process highlights a large degree of simultaneity in the system, with some especially important simultaneity effects in the price equation. Allowing for the simultaneity substantially changes the coefficients of many predictors of home prices, reversing the implied causality in many cases. Simultaneity in the endogenous variables also affects the coefficients of variables not included in the system, so that the simultaneity is not "benign” even with respect to exogenous variables' effects.

The rest of this article is organized as follows. The next section provides some background on the Empowerment Zone program and previous literature. Section III discusses our data, empirical model and identifying assumptions. Section IV presents the results, which are discussed in section V. A final section concludes with some policy implications and suggestions for future research.

\section{BACKGROUND}

Neighborhood dynamics and simultaneity As Rosenthal (2008) points out, neighborhood change is a pervasive aspect of American urban environments. The changing fortunes of neighborhoods have been understood 
through comparative static analyses (such as changing transportation costs in the classic Alonso/Muth models) as well as in more dynamic models such as the Schelling model of neighborhood tipping (Schelling, 1969, 1971), or models of neighborhood succession/filtering (Brueckner, 1980; Bond and Coulson, 1989; Bruekner and Rosenthal, forthcoming) and various other dynamic models (Miyao, 1987).

The empirical examination of neighborhood change by economists is not as well developed, partly because the data requirements are considerable. Aaronson (2001) looks at the question using vector auto-regression, finding the interactions between his neighborhood variables are substantial, but that shocks to neighborhood characteristics tend to dissipate over time. A similar stability is found in Galster et al. (2007) across five cities and several neighborhood characteristics. Rosenthal (2008) shows that neighborhoods change over very long cycles and that change is driven by several neighborhood characteristics. Card et al. (2007) estimate neighborhood tipping points in the tradition of Schelling, and find that city-specific tipping points correlate sensibly with metropolitan political and opinion measures.

Noonan et al. (2007) and Krupka and Noonan (2009) look at the neighborhood as a system of equations in estimating various policy interventions. In those papers - as well as here - the estimates show that the measurement of policy effects can be sensitive to how the empirical specification treats the simultaneity amongst the variables. In those earlier papers, however, the simultaneous system takes a back seat to the estimation of the policy effects. Here, with a more parsimonious system, we are able to explore the simultaneity more closely, as well as compute the policy effects. 
Previous work on neighborhood change has taken multiple empirical strategies. Earlier related work uses single-equation models to describe neighborhood change, but these approaches are limited in their ability to capture the complex interplay among various neighborhood indicators. Unlike Aaronson's (2001) earlier multi-equation VAR model, we use smaller units of analysis and more indicators, and our simultaneousequations approach imposes a different structure on the relationship between the variables, allowing for contemporaneous as well as lagged influence of system variables, and relying on predetermined variables as instruments to identify the parameters of endogenous variables. Similar to Aaronson (2001), Noonan et al. (2007) and Rosenthal (2008), our approach captures neighborhood dynamics by explicitly modeling how past neighborhood characteristics affect future equilibria. The primary departure in this analysis is the emphasis on how these characteristics are simultaneously determined (or how they co-evolve).

\section{Spatially targeted policy and the Empowerment zone program}

Spatially targeted policies have been popular with both the federal and state governments despite Winnick’s (1966) well articulated argument against them. These policies can be seen as addressing the spatial mismatch between inner-city, low-skill labor supply and suburban and exurban low-skill labor demand, as characterized by Kain (1968). Another possible justification for these programs is budgetary. Evidence presented in Bartik (1991) suggests that localized tax incentives could actually be revenue enhancing, at least from the considerably limited perspective of the targeted area. 
Many of the costs of spatially targeted economic development programs come from tax incentives. Typically, targeted areas are selected based on some set of needbased criteria. During the 1980's many states created such programs. Generically these programs are referred to as "enterprise zones"1 ${ }^{1}$ where employers were given economic incentives to create jobs specifically in these depressed areas. These economic incentives can include lighter regulatory burdens and tax abatements. Peters and Fisher (2002) provide some historical background on the inception and adaptation of these programs.

The federal role begins with Empowerment Zones and Enterprise Communities Act of 1993 (as Title XIII of the Omnibus Budget and Reconciliation Act of 1993). This policy was a major component of the Clinton Administration's urban policy following the Los Angeles riots in 1992. The Empowerment Zone program coupled tax incentives and wage credits with large amounts of federal funding for community development. More than just job stimulus through tax incentives, the EZ program required community partnerships to address broader economic and social conditions, which marked a departure from previous federal urban renewal projects (Oakley and Tsao, 2007b).

For the urban EZ program, HUD reviewed proposals from cities and awarded EZ designations. Between the competition’s announcement in January 1994 and a June 1994 deadline, 78 cities applied for the EZ program. ${ }^{2}$ The extensive application process solicited proposals that combined innovative programs, detailed maps and census data

\footnotetext{
${ }^{1}$ Terminology in this area can be confusing as state and federal programs have various yet similar names and fall under the broader category of enterprise zones, which are often also given the abbreviation of "EZ". Throughout this discussion, we refer to federal Empowerment Zones as EZs and use the term "enterprise zone" in reference to the many, less-generous state and local place-based initiatives.

${ }^{2}$ Eligibility was based on population of the proposed EZ, economic conditions and geographic size, certain minimum poverty rates in EZ census tracts, not being more than three contiguous parcels, location within a single state and jurisdiction of nominating local government and not including the CBD in the zone generally (Oakley and Tsao, 2006).
} 
and participation and funding from private and public actors. This application process is described and analyzed in Wallace (2003, 2004), Greenbaum and Bondonio (2004), Hanson (2008) and Busso and Kline (2008).

EZs sought to enhance both human and physical capital as well as promote broader community revitalization. Designated urban EZs each received \$100 million in federal (Title XX SSBG) funds plus tax incentives ${ }^{3}$ (employment tax credits ${ }^{4}$, accelerated depreciation and tax-exempt facility bonds) for businesses located inside the zone. The SSBG funds could be spent promoting employment, social services, housing and homeownership and transportation (Oakley and Tsao, 2006). The host municipalities could also issue tax-exempt bonds to fund additional improvements to the areas. The federal benefits package accompanying EZ designation was for the most part uniform across zones through our data period.

The original eight EZs contained almost 350 census tracts and one million residents. Two later rounds of the program swelled these figures to over 700 census tracts with a combined population of over two million individuals in 31 zones (Hanson, 2008; Greenbaum and Bondonio, 2004). Figure 1 shows the distribution of MSAs with EZs across the three rounds. EZ program benefits are slated to sunset in 2009, making an evaluation of its effects especially timely.

\footnotetext{
${ }^{3}$ Businesses were allowed a tax credit of up to $20 \%$ of the first $\$ 15,000$ in wages paid to zone residents,; an increased section 179 tax deduction at \$20,000 more than usual annual depreciation and lower-interest commercial loans for some facilities. See Hanson (2008) and Busso and Kline (2008) for more details.

${ }^{4}$ The two SEZs (Los Angeles and Cleveland) did not receive the tax credit until 1999 (Busso and Kline, 2008).
} 
Figure 1: Empowerment Zone MSAs across all three rounds.

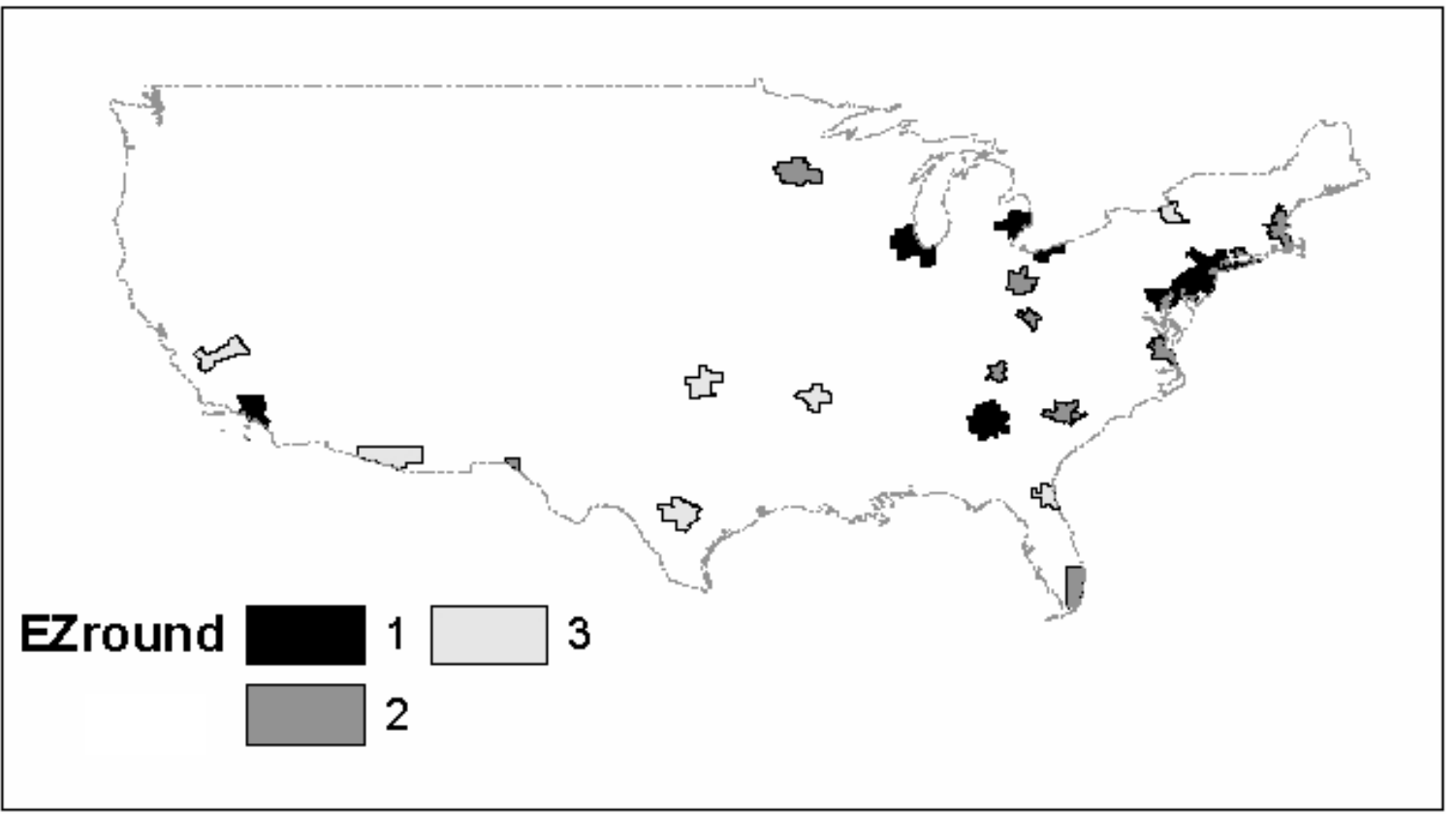

Until recently, state programs were the subject of most research examining the effects of spatially targeted incentives. Such research is vulnerable to a host of methodological problems, as outlined by Boarnet (2001), chief among which is the nonrandom selection of areas for aid. Peters and Fisher (2002) critically review the literature up to that point. They describe an initial spate of favorable evaluations ${ }^{5}$ followed by studies showing much smaller or insignificant effects. ${ }^{6}$ They posit that the tax incentives were too weak or too qualified to make a difference. Bondonio and Greenbaum (2007) show that countervailing positive effects on new firms and negative effects on existing firms (that exit the zone) account for the insignificant net effects.

\footnotetext{
${ }^{5}$ Erickson and Friedman (1990), Papke (1993) and Papke (1994) are examples.

${ }^{6}$ Boarnet and Bogart (1996), Greenbaum (1998), Greenbaum and Engberg (2000), Engberg and Greenbaum (1999), Bondonio and Engberg (2000) and Peters and Fisher (2002) all point towards this conclusion. Elvery (2009), Lynch and Zax (2008) and Landers (2006) are some more recent analyses that find insignificant results of enterprise zone status.
} 
The literature examining the effects of the federal Empowerment Zone program is less developed. Oakley and Tsao (2006, 2007a, b) use propensity score matching to examine the effect of Empowerment Zones on several socio-economic neighborhood outcomes in four cities, with a focus on Chicago. They find some localized effects on poverty and related variables in the case of Chicago's zone, but characterize the effects as underwhelming.

Recently, a series of papers have appeared taking a national perspective on the EZ program. Busso and Kline (2008) use propensity score matching and find positive direct effects along a number of dimensions, including employment, poverty and housing prices. Hanson (2008) uses instrumental variables to show that the estimates of positive employment effects suffer from endogeneity bias. He does find significant and substantively large program effects on housing values. Finally, Krupka and Noonan (2009) show positive direct effects on housing values, but mixed results on other neighborhood variables. This paper contributes to that stream of literature, provides evidence on the robustness of those results and extends that work by exploring the simultaneity bias that will be present in single-equation models using similar data.

\section{Empirical Strategy}

\section{Data}

Data for this article came from the US Census for the census years of 1980, 1990 and 2000. ${ }^{7}$ The unit of observation is the block-group as defined in the 2000 census, which we call the "neighborhood.” The other data came from HUD (EZ data) and various GIS

\footnotetext{
${ }^{7}$ The census data came from Geolytics Inc., which provides spatial data over time in a constant geography.
} 
sources such as the National Atlas (distance to historic city center). Neighborhood aggregate data are used to estimate the system of equations described below. ${ }^{8}$ We restrict our attention to a sample of roughly 100,000 metropolitan block groups.

\section{Model}

The empirical model here is similar to the one developed in Krupka and Noonan (2009).

The model is a multi-equation, partial-adjustment model, where neighborhood home values interact with neighborhood demographics and housing stock characteristics in a system of equations. To reduce the risk of omitted variables bias, all equations are estimated in differences.

Equation (1) $\quad \dot{P}_{i t}=\beta_{t}+\beta_{P} \dot{P}_{i t-1}+\beta_{E Z} \dot{E} Z_{i t}+\beta_{S} \dot{S}_{i t}+\beta_{N} \dot{N}_{i t}+\beta_{M} \dot{M}_{i t}+\dot{\varepsilon}_{1 i t}$

where $t$ indexes time, $i$ indexes neighborhoods, $\dot{X}_{i t}=X_{i, t}-X_{i, t-1}$ for any variable $X, P$ is the median house value, $S$ is a vector of structural characteristics of the neighborhood housing stock, $N$ is a set of neighborhood demographic characteristics and $M$ is a vector of municipal characteristics such as public services, school quality and taxes that may vary with time. The $E Z$ variable allows EZ program participation to have an effect on

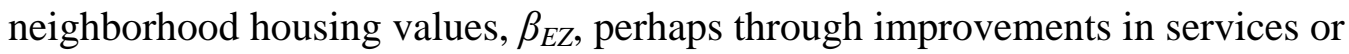
neighborhood infrastructure and amenities. We call this effect of $E Z$ on neighborhood housing values the direct effect of the program because the effect is not transmitted

\footnotetext{
${ }^{8}$ While our use of neighborhood aggregate data limits our ability to infer price effects at the individual level, some research has shown that aggregate data can be used to generate reasonably accurate estimates of first-stage hedonic effects (Freeman, 1979; Nelson, 1979; O’Byrne et al., 1985; Noonan et al., 2007; Greenstone and Gallagher, 2008). Moreover, the median housing value in a neighborhood is important in its own right. Understanding the effects of policy on neighborhood aggregate prices should be of interest to governments in designing such policies and to developers in deciding where to direct investment in response to such policies. The results based on such aggregate measures can be viewed as the effects of average policy exposure on average outcomes.
} 
through other variables. Because equation (1) is differenced, $\beta_{E Z}$ can be thought of as the difference-in-differences estimator of the average treatment effect. ${ }^{9}$

The equations describing the evolution of neighborhood housing stock and demographic characteristics are similar to the price equation:

Equation (2) $\quad \dot{S}_{i t}=\gamma_{t}+\gamma_{S} \dot{S}_{i t-1}+\gamma_{E Z} \dot{E} Z_{i t}+\gamma_{N} \dot{N}_{i t}+\gamma_{P} \dot{P}_{i t}+\gamma_{M} \dot{M}_{i t}+\dot{\varepsilon}_{2 i t}$.

Equation (3) $\quad \dot{N}_{i t}=\delta_{t}+\delta_{N} \dot{N}_{i t-1}+\delta_{E Z} \dot{E} Z_{i t}+\delta_{S} \dot{S}_{i t}+\delta_{P} \dot{P}_{i t}+\delta_{M} \dot{M}_{i t}+\dot{\varepsilon}_{3 i t}$.

In equations (2) and (3), $S$ and $N$ respond to $P$ and to one another because of sorting in and out of the neighborhood and investment decisions by households and developers. EZ program status might affect $S$ and $N$ because the program's local implementation may spur certain kinds of development or make the neighborhood more attractive to certain demographic groups more than others.

This system of three equations can be represented in matrix notation:

Equation (4) $\left[\begin{array}{ccc}1 & -\beta_{S} & -\beta_{N} \\ -\gamma_{P} & 1 & -\gamma_{N} \\ -\delta_{P} & -\delta_{S} & 1\end{array}\right]\left[\begin{array}{c}\dot{P}_{i t} \\ \dot{S}_{i t} \\ \dot{N}_{i t}\end{array}\right]=\left[\begin{array}{c}\beta_{E Z} \\ \gamma_{E Z} \\ \delta_{E Z}\end{array}\right] \dot{E Z}_{i t}+\left[\begin{array}{c}\beta_{M} \\ \gamma_{M} \\ \delta_{M}\end{array}\right] \dot{M}_{i t}+\left[\begin{array}{c}\beta_{t}+\beta_{P} \dot{P}_{i t-1}+\dot{\varepsilon}_{1 i t} \\ \gamma_{t}+\gamma_{S} \dot{S}_{i t-1}+\dot{\varepsilon}_{2 i t} \\ \delta_{t}+\delta_{N} \dot{N}_{i t-1}+\dot{\varepsilon}_{3 i t}\end{array}\right]$

To generate estimates of the "full effect" from our model, the coefficients from equations (1)-(3) must be combined in the appropriate way. The full effect is derived by taking the system of equations (1) through (3), totally differentiating and using Cramer's Rule to solve for the total derivative of $P$ with respect to $E Z$. We end up with:

Equation (5) $\frac{d \dot{P}}{d \dot{E} Z}=\frac{\beta_{E Z}+\beta_{S} \gamma_{E Z}+\beta_{N} \delta_{E Z}+\beta_{S} \gamma_{N} \delta_{E Z}+\beta_{N} \delta_{S} \gamma_{E Z}-\beta_{E Z} \gamma_{N} \delta_{S}}{1-\beta_{S}\left(\gamma_{N} \delta_{P}+\gamma_{P}\right)-\beta_{N}\left(\delta_{S} \gamma_{P}+\delta_{P}\right)-\gamma_{N} \delta_{S}}$

\footnotetext{
${ }^{9}$ Actually, all of our analyses are carried out in the presence of metropolitan-area fixed effects, so that the coefficient can be thought of as thrice-differenced, or difference-in-difference-in-differences estimate.
} 
The direct effect of program participation on home values appears as the first term in the numerator. The indirect effects of EZ on price through $S$ and $N$ appear as $\beta_{S} \gamma_{E Z}+\beta_{N} \delta_{E Z}$, while the additional effects on $P$ that occur through the interaction of $S$ and $N$ appear as $\beta_{S} \gamma_{N} \delta_{E Z}+\beta_{N} \delta_{S} \gamma_{E Z}$. The denominator represents a sort of “multiplier process": $1-\beta_{S}\left(\gamma_{N} \delta_{P}+\gamma_{P}\right)-\beta_{N}\left(\delta_{S} \gamma_{P}+\delta_{P}\right)$. These effects are more or less intuitively clear. However, the careful algebraic derivation of the full effects alerts us to two terms which correct for double counting: $-\beta_{E Z} \gamma_{N} \delta_{S}$ in the numerator and $-\gamma_{N} \delta_{S}$ in the denominator. A nice feature of this approach is that the method used to derive it generalizes to more complicated empirical settings with more than three equations. Here we carry out the analysis with nine equations.

We estimate the model represented above as a system of equations, which allows us to account for the simultaneity implicit in the rich interactions among $P, S$ and $N$. It is not possible to estimate these models simultaneously unless we have instruments for each endogenous variable. These instruments must be correlated with the independent variable, but not correlated with the error term in each equation. Our theory suggests that the set of twice-lagged levels of each main variable will serve as appropriate instruments for $\dot{P}, \dot{S}, \dot{N}$ and their lags (when present) and will just identify the system.

In all the above, we have been implicitly assuming that the causal effect of EZ program participation is identified in our models. The work by Greenbaum and Bondonio (2004) and much of the literature on the state programs (Boarnet, 2001) suggests that this assumption is overly optimistic. To identify causal effects, we employ two methods. Our preferred method uses a comparison group to serve as a 
counterfactual. We alternatively use an auxiliary regression of congressional variables inspired by Hanson (2008).

In the comparison group strategy, we leverage the timing of the program to identify a set of block groups that represent what would have happened to EZ neighborhoods had they not benefited from the EZ program. The program had three rounds, in 1994, 1998 and 2001. Because our data end in 2000, there can be no causal effect of third round designations on any of our neighborhood variables. However, because all of these neighborhoods are distressed, the experiences of distressed neighborhoods designated in the third round serve as a reasonable counterfactual for the experiences of distressed neighborhoods designated in the first round. Two sets of facts support the validity of this identifying assumption. The first is that changes in very few of our neighborhood variables over the 1980s differ substantively across rounds. Second, the metropolitan-standardized changes in prices over the 1980s were statistically indistinguishable between zones designated in the first and third rounds. Both of these considerations support our contention that, at the beginning of the 1990s, both round 1 and round 3 EZ neighborhoods were distressed and likely to face a further decade of relative decline. The similarity of the trends leading into the policy period suggests that the trends in absence of the policy intervention would have continued to be similar over the 1990s.

Because the identifying assumptions of our preferred “comparison group” strategy cannot be tested, we also replace round 1 designations with a predicted value of the variable fitted from an auxiliary probit. This is in the spirit of instrumental variables estimation. The predictors in this auxiliary model include a vector of congressional 
variables and lagged differences (1980-1990) and twice-lagged levels (1980) of the $S, N$ and $M$ vectors, except for school expenditures which were not available for 1980. Congressional variables measured at the block-group level are: years of seniority of the most senior senator; total seniority of senators; count of senators on Appropriations committee, count of senators on the Banking, Housing and Urban Affairs committee; years of seniority of the most senior senator on that committee; count of representatives for that block group and count of democratic representatives for that block group. ${ }^{10} \mathrm{~A}$ test of whether the congressional variables are jointly insignificant in the auxiliary probit is rejected at the 0.0001 level, indicating that politics strongly predicts selection as an EZ. The results from this alternative identification strategy, reported below, lead us to believe that our preferred strategy is conservative.

\section{Variables}

There are four arrays of variables used here: $P, N, S$ and $M$. Table 1 presents the mean changes from 1990 to 2000 for all the variables for which results are reported. This table presents means for the MSA sample and various subsamples of block groups participating in different EZ rounds. ${ }^{11}$

Price $(P)$ is measured with the log of the median housing value $(\ln (M d . V a l)$.$) as$ reported in the census long form. Neighborhood characteristics $(N)$ are comprised of four variables (that also come from the census): proportion of families with at least one worker (Workers), proportion of households with incomes at or below 150 percent of the poverty line (Poverty), proportion of households that have children (Children) and

\footnotetext{
${ }^{10}$ Alternative variables describing House committee membership variables were not used because they overpredict EZ participation.

${ }^{11}$ It is worth noting the strong appreciation of round 1 Empowerment Zones and the weak appreciation of round 3 Empowerment Zones.
} 
proportion of the population aged over 25 with a college degree (College). All these variables are measured as changes from 1990 to 2000 in Table 1 . These variables were chosen because they have been shown in hedonic studies to affect housing values and because they are variables of special interest in the local economic development literature.

The housing stock variables (S) include average number of rooms (Rooms), the population density (Density), the proportion of residents renting their property (Renters) and the proportion of the housing stock built within the preceding decade (New Units).

All these variables are measured as changes from 1990 to 2000 in Table 1.

Table 1: Means and standard deviations for 1990's changes, main variables.

\begin{tabular}{|c|c|c|c|c|c|}
\hline & \multirow[b]{2}{*}{ [Abbreviation] } & \multicolumn{4}{|c|}{ Sample } \\
\hline & & All Metro & Round 1 & Round 2 & Round 3 \\
\hline \multirow{5}{*}{$E Z$} & Round $1 \mathrm{EZ}$ & 0.0084 & $960^{a}$ & 0 & 0 \\
\hline & Round 2 EZ $\quad$ [EZ1] & $\begin{array}{c}0.0911 \\
0.0086\end{array}$ & 0 & $987^{a}$ & 0 \\
\hline & {$[E Z 2]$} & 0.0924 & & & \\
\hline & Round 3 EZ & 0.0057 & 0 & 0 & $656^{\mathrm{a}}$ \\
\hline & [EZ3] & 0.0754 & & & \\
\hline \multirow{2}{*}{$P$} & log median home value & 0.3900 & 0.6278 & 0.3967 & 0.2672 \\
\hline & {$[\ln ($ Md.Val. $)]$} & 0.3210 & 0.5934 & 0.4019 & 0.3538 \\
\hline \multirow{8}{*}{$N$} & prop. Working families & 0.0046 & 0.0865 & 0.0352 & 0.0390 \\
\hline & [Workers] & 0.0957 & 0.1741 & 0.1489 & 0.1467 \\
\hline & $150 \%$ poverty rate & 0.0006 & -0.0377 & -0.0230 & -0.0307 \\
\hline & [Poverty] & 0.1058 & 0.1909 & 0.1395 & 0.1713 \\
\hline & prop. w/children & -0.0013 & 0.0054 & -0.0021 & -0.0047 \\
\hline & [Children] & 0.0666 & 0.1023 & 0.0816 & 0.0958 \\
\hline & prop. with college $(25+)$ & 0.0514 & 0.0316 & 0.0341 & 0.0242 \\
\hline & [College] & 0.0891 & 0.0967 & 0.0966 & 0.0790 \\
\hline \multirow{8}{*}{$\mathbf{S}$} & Population density & 280.47 & -512.52 & -580.46 & -136.75 \\
\hline & [Density] & 2372.7 & 4527.1 & 8146.8 & 1990.9 \\
\hline & avg. rooms & 0.0641 & 0.0401 & 0.0638 & 0.0789 \\
\hline & [Rooms] & 0.5041 & 0.7512 & 0.5514 & 0.6116 \\
\hline & prop. Renters & -0.0068 & -0.0244 & -0.0091 & 0.0092 \\
\hline & [Renters] & 0.1087 & 0.1528 & 0.1119 & 0.1441 \\
\hline & prop. housing built in 10 years & -0.0672 & -0.0253 & -0.0413 & -0.0370 \\
\hline & {$[$ New Units $]$} & 0.1929 & 0.1456 & 0.1408 & 0.1285 \\
\hline \multirow[t]{3}{*}{$M$} & Place: log of households & 0.1408 & 0.0007 & 0.0335 & 0.1361 \\
\hline & [Muni.HoHos] & 0.1539 & 0.0624 & 0.1004 & 0.0368 \\
\hline & Place: log of median home value & 0.3784 & 0.4272 & 0.3506 & 0.2807 \\
\hline
\end{tabular}




\begin{tabular}{|c|c|c|c|c|}
\hline $\begin{array}{c}{[\text { Muni.Vals] }} \\
\text { Place: log of median income }\end{array}$ & $\begin{array}{c}0.2072 \\
0.2829\end{array}$ & $\begin{array}{c}0.3419 \\
0.2799\end{array}$ & $\begin{array}{c}0.1242 \\
0.2633\end{array}$ & $\begin{array}{c}0.0815 \\
0.2693\end{array}$ \\
\hline $\begin{array}{c}\text { [Muni.Inc] } \\
\text { District: log expend per pupil. }\end{array}$ & $\begin{array}{c}0.0895 \\
0.5007\end{array}$ & $\begin{array}{c}0.1236 \\
0.5270\end{array}$ & $\begin{array}{c}0.0583 \\
0.4594\end{array}$ & $\begin{array}{c}0.0479 \\
0.5221\end{array}$ \\
\hline [Dist.PPExp] & 0.2093 & 0.0873 & 0.1805 & 0.2034 \\
\hline No. obs (all variables) b & 109,905 & 749 & 846 & 608 \\
\hline
\end{tabular}

a. Numbers for mean values of the EZ variables for the EZ round subsamples are counts of block groups for which the specified variables are equal to one. Means are shown for all variables, with standard deviations in smaller print below. b. The number of observations represents the minimum number of observations across all variables. The variable with the least observations is always the price variable.

The variables discussed thus far are all endogenous in the system of equations model. Several exogenous variables are also included in the analysis. The municipallevel variables $(M)$ are measured at the census-defined place level, which is the closest approximation to municipalities available. These local public finance variables are considered exogenous because an individual block group generally makes up a smallenough proportion of the place containing it that it will not affect these broader averages. They include measures for the logs of the number of households (Muni.HoHos), the median housing value (Muni.Vals) and median income (Muni.Inc). ${ }^{12}$ Also included is a variable derived from the National Center for Education Statistics (NCES) School District Demographic System (SDDS) and the 1992 and 2002 Census of Governments measuring per-pupil expenditure in the elementary or unified school district that contains the centroid of the block group (Dist.PPExp) as a measure of public service quality. These variables are measured as changes from 1990 to 2000 in Table 1.

Finally, three dummy variables constitute our variables of interest (EZ). They capture whether the observation was designated in one of the three rounds of the EZ initiative. Dummy variables indicating designation in the first or second rounds are EZ1

\footnotetext{
${ }^{12}$ If a block-group is not in any Place, then county-level values for these variables are substituted, because unincorporated areas generally get public services from county governments.
} 
and EZ2, respectively. EZever takes the value of unity if the block group was ever in an EZ, and zero otherwise, thus implicitly capturing selection in the third round in 2001. This specification allows for easier interpretation of round 1 selection relative to the round 3 comparison group, as previously described. It uses EZever as a control for neighborhood hardship not already captured in the $S, N$ and $M$ vectors, so that the coefficient for EZ1 indicates the differential effect of designation in the first round when the policy might have had time to affect outcomes by 2000. When the auxiliary regression is used to identify causal effects, the additional EZ2 and EZever control variables are not necessary.

We also include in all regressions a set of time-invariant controls. In every equation, all variables are measured as differences from metropolitan averages. This is equivalent to estimating all equations with metropolitan fixed effects. Because the equations are estimated in differences, this means that each metropolitan area is allowed to have its own city-specific trend in prices and the other endogenous variables, and all our coefficients are identified off of deviations from metropolitan-wide trends. Moreover, in the price equation we also include a set of interactions between the distance of each block group to the nearest historic city center (National Atlas of the United States, 2004) and the metropolitan area. This allows every metropolitan area to have its own change in the metropolitan area's "rent gradient."13

\section{RESULTS}

\footnotetext{
${ }^{13}$ This also provides scores of additional instruments for the non-price equations in the system.
} 
The estimated results are reported in tables 2, 3, 4 and 5. Table 2 includes the results for simple OLS estimations. Columns 2.1 and 2.2 use the comparison group identification strategy, while columns 2.3 and 2.4 use the auxiliary regression to identify estimates of causal effects. Across the board, the EZ policy effects are substantial and positive. The conservative estimates put the direct effect of being in EZ round 1 at about $27 \%$ while the auxiliary regressions put the direct policy effect on home values at almost $60 \%$ ! Columns 2.2 and 2.4 drop the endogenous variables from the regression. This is a simpler way of getting estimates of the indirect effects. One can think of the policy effects in columns 2.1 and 2.3 as the "all else equal” estimates of the policy effect: the effect of the policy on housing values holding all demographic and housing stock variables fixed. On the other hand, if we drop those demographic and housing market variables from the model, we essentially allow these variables to vary. Thus, if EZ program participation increases housing values directly but also increases them indirectly (through poverty reduction, for instance), dropping the intermediate endogenous variables allows the indirect effects of program participation to be included in the coefficient on EZ1.

Looking at the estimates of the indirect effects from Table 2, we see that these estimates are negative (the "full effects" estimates in columns 2.2 and 2.4 are smaller than the "direct effect” estimates in columns 2.1 and 2.3) but the differences are quite small relative to the uncertainty about these estimates. The coefficients on the rest of the variables ( $S, N$ and $M$ ) are generally easily interpretable. Interpreted as hedonic prices, the results suggest that new construction is an amenity (in that people are willing to pay 
more to live in neighborhoods with more construction), while the presence of children is a disamenity.

The results of our systems of equations estimations are reported in Table 3 for the comparison group strategy and Table 4 for the auxiliary probit strategy. In these tables, the regressors are listed along the left side, and each column represents a different equation in our system. The direct effects of EZ program participation on all the endogenous variables can thus be read across the top row of both tables and the effect of each variable on home values can be read down the left-most column. In each table, the coefficients of each dependent variable's own lag are boxed out, and these coefficients can be read along the diagonal.

The results are broadly similar across identification strategies. The EZ1 coefficient is significant and positive in the home value equation, and the coefficients are of similar magnitude across strategies, in the high teens, implying an approximately $20 \%$ effect on home values. EZ program participation also appears to have positive effects on poverty, proportion of families with children, the proportion of households who own their homes and the number of rooms. The program had negative effects on proportion of college educated and population. ${ }^{14}$ Finally, the effects of program participation on construction of new homes and the proportion of families who work are inconsistent across identification strategies. The program effects on these variables are negative and insignificant in the comparison group strategy (Table 3), but positive and significant in the auxiliary probit strategy (Table 4).

\footnotetext{
${ }^{14}$ Recall that the areas compared are held constant, so this change in population is not an artifact of changing geographical definitions of the units of analysis.
} 
The models reported here show mixed results of the federal EZ program. We may be satisfied in the increase in owners and children, while frustrated with the increase in poverty and decrease in college educated. The lack of a consistent effect on labor market outcomes of residents is also problematic, as the improvement of labor market outcomes for zone residents is one of the primary goals of the program.

The rest of the results in tables 3 and 4 are less relevant to the policy's aims, but more interesting in what they reveal about neighborhood dynamics. The lagged variables in each equation are (as expected) positive and significant in all cases except for in the cases of poverty and children (the lagged children variable is positive and significant in the Children equation in Table 4, however). The effects of the endogenous variables on one another are generally significant. This reinforces the importance of the complex, simultaneous system of interactions among disparate characteristics that are embodied by neighborhoods. Most of the variables have reinforcing effects on each other. For instance, increased poverty decreases the proportion of workers, while increased proportion of workers decreases the poverty rate in turn. There are a few exceptions to this pattern, most of which involve home values. One exception that does not involve home values is the interaction between renters and families with children. The results show that increasing the proportion of renters in a neighborhood will increase the number of families with children, while an increase in the number of families with children will decrease the number of renters (the first effect is insignificant in Table 4).

The interaction between neighborhood home values and the other endogenous variables is also interesting because the changes they represent (relative to the OLS estimates in Table 2) shed light on the simultaneity bias present in the more naïve model. 
Two interesting examples are the proportion of households with children and the construction of new housing. In the OLS models, new construction was positively correlated and proportion with children was negatively correlated with home values. A possible interpretation of these coefficients is that the presence of children is a disamenity and that new housing is an amenity. Once the simultaneity bias is accounted for, however, we see the causation in these relationships runs in the opposite direction; new construction has no effect on median home values, and children increase the value of homes in a neighborhood (these are the coefficients in the first column of tables 3 and 4). The correlation observed in the OLS models is explained by examining the row reporting the effect of higher home values on other endogenous variables; higher home values push out families with children and make the construction of new homes more attractive for developers (these coefficients are from the fourth row of Table 3 and the second row of Table 4). Similar stories occur with other endogenous variables, although the changes are usually a matter of magnitude or significance, not sign. ${ }^{15}$

With these results in hand, it is straightforward to produce estimates of the full effects of the EZ policy on the selected neighborhoods. Table 5 reports these results for housing value or "price" across all four models estimated above. The first column of numbers reports the direct effect: the EZ1 coefficient from the price equations in columns 1 and 3 of Table 2 and the first cell of tables 3 and 4 . The second column reports the estimates of the full effect from the columns 2 and 4 of Table 2 or as computed using an expanded equation (5) and the coefficients from tables 3 and 4 . The last columns report

\footnotetext{
${ }^{15}$ It is worth noting here that similar models run with spatial spillovers into nearby neighborhoods deliver results that are quite consistent with the results reported above. The spillover effects were found to be positive and significant.
} 
the indirect effect and the indirect effect as a proportion of the standard error of the direct effect as measures of the magnitude of the changes that come through the system.

Table 5: Direct, full and indirect price effects of EZ policy.

\begin{tabular}{|c|l|c|c|c|c|}
\hline & & $\begin{array}{c}\text { Direct } \\
\text { Effect }\left(\boldsymbol{\beta}_{E Z}\right)\end{array}$ & $\begin{array}{c}\text { Full Effect } \\
\left(\boldsymbol{b}_{E Z}\right)\end{array}$ & $\begin{array}{c}\text { Indirect } \\
\text { Effect } \\
\left(\boldsymbol{b}_{E Z}-\boldsymbol{\beta}_{E Z}\right)\end{array}$ & $\left(\boldsymbol{b}_{E Z}-\boldsymbol{\beta}_{E Z}\right) / \mathbf{s e}\left(\boldsymbol{\beta}_{E Z}\right)$ \\
\hline \multirow{2}{*}{ OLS } & Comparison & 0.2392 & 0.2221 & -0.0171 & -0.67 \\
\cline { 2 - 6 } & Auxiliary & 0.4385 & 0.4205 & -0.0181 & -0.38 \\
\hline $\begin{array}{c}\text { System of } \\
\text { Equations }\end{array}$ & Comparison & 0.1963 & 0.2245 & 0.0282 & 1.57 \\
\cline { 2 - 6 } & Auxiliary & 0.1763 & 0.2237 & 0.0475 & 1.65 \\
\hline
\end{tabular}

Across the different identification assumptions and estimation techniques, a broadly consistent pattern of small indirect effects emerges from Table 5. These effects are small and insignificant when identified with OLS. By contrast, they are positive and more substantial in the system of equations analysis. These results are qualitatively similar to those in Krupka and Noonan (2009), who also find large, positive direct effects and generally small indirect effects. While the indirect effects in the system of equations are positive, we wish to stress here their small size in comparison to the direct effects of the program.

\section{DISCUSSION}

Findings suggest the EZ program can increase the median price of homes by over $20 \%$ on average, a rather large effect. These numbers reinforce the consensus of the most recent studies (Krupka and Noonan, 2009; Busso and Kline, 2008; Hanson, 2008). The large direct effects relative to the smaller effects of state programs as discussed in Greenbaum 
and Engberg (2000) are probably due to higher generosity ${ }^{16}$ and visibility of the program on the substantive side and the better measurement of program participation on the statistical side. The similarity of the program effects between Table 3 and Table 4, and with regard to those reported in other recent studies is reassuring.

The coefficient on EZever is negative and significant in Table 3. This implies that if the first round EZ block groups had not gotten the EZ policy intervention, they would have been witness to substantial declines in home values over the 1990s. The EZever coefficient is also likely picking up the “distressed neighborhood” effect that would bias down the coefficient on EZ1 (if EZever was not also included). Interestingly, the EZever coefficient is not statistically significant in any of the other equations in Table 3, suggesting that the decline of the neighborhood was limited in some sense to the housing market.

Overall, it should be noted that the EZ effects (in tables 3 and 4), are often significant, although not always in the direction program advocates may have hoped. It appears that the Empowerment Zone policy intervention (besides boosting home values) increased neighborhood poverty, the proportion of households with children, and the average number of rooms in dwellings. It also decreased population density (and thus population), the proportion renters, and the proportion of adults with college degrees. These effects are not all in the direction that program planners might have hoped. Because of these mixed policy effects the indirect effects associated with them tend to be small relative to the direct effect of the policy. The minimal or offsetting effects of the

\footnotetext{
${ }^{16}$ GAO (1999) estimates that round 1 EZs would cost $\$ 2.5$ billion over the first ten years. Busso and Kline (2008) note an estimate of four dollars of non-federal funds spent for every dollar of SSBG funds in round 1 EZs. Concentrating such support in six EZs with fewer than a million total residents might indeed reasonably be expected to have sizeable effects.
} 
policy through channels other than direct effects on housing values is surprising given the goals of the program.

Although indirect price effects appear minimal, the direct price effects observed in tables 3 and 4 point to an important story. There is a temptation in regressions of house values on neighborhood attributes to interpret the coefficients as representing the marginal willingness to pay for these neighborhood attributes. Because our dependent variable is similar to the dependent variable in such a first stage hedonic, there is a similar temptation here. The changes between the OLS and systems coefficients highlights that this temptation should be resisted, at least with aggregate data such as ours. Newer houses might sell for more, while older/historic neighboring houses might be an amenity. Similarly, families with children might buy cheaper houses, while the presence of children in a neighborhood could nonetheless increase home values. Using aggregate data means that one must be careful to distinguish between composition effects (a group of newer houses will be more expensive on average) and externality effects (a group of newer houses makes a neighborhood more desirable). In this context, the potential endogeneity of neighborhood composition becomes a serious issue.

The simultaneity bias is evident in comparing Column 2.1 (or 2.3) to the first column in Table 3 (or 4) where neighborhood attributes are simultaneously determined. Here, price is not merely a function of (or composed by) structural $(S)$ and demographic $(N)$ features; price also affects those features. The simultaneous co-determination of $P, S$ and $N$ in equilibrium forms the essential backdrop of our empirical investigation of neighborhood composition. Such a framing contrasts with the common framing of some attribute (e.g., $P$ ) simply being determined by the other attributes. Interpreting hedonic 
price gradients as the "effects" of attribute changes on prices relies on the exogeneity of those attributes. If the model for Column 2.1 parallels the hedonic price model, then the model in Table 3 relaxes this assumption.

The substantial changes in the coefficients of our estimated direct effects between Table 2 and tables 3 and 4 suggest that, at least with aggregate data, the simultaneity is not benign in the sense that the coefficients of exogenous variables (those not included in the system) are sensitive to the specification. This is not so surprising; if the coefficients of the endogenous variables in the OLS regressions are biased because they are assumed exogenous, the entire coefficient vector will be biased in difficult-to-predict ways. This is evidenced by the change in the estimated effects of round 1 EZ selection (a 0.04 change in coefficient in the comparison group strategy and a more substantial change of over 0.2 in the auxiliary regression strategy) when we move from a single equation to a simultaneous equations setting. A similar shift occurs with the coefficient of EZever, which represents our counterfactual. It is also evident in the coefficients on the municipal-level variables, which exhibit large changes between the single-equation estimates and the simultaneous equations approach. This means that the bias implicit in assuming away simultaneity is not limited to the endogenous variables, but potentially affects all variables, including those of special interest. Econometricians estimating effects in the context of neighborhood change - or any potentially simultaneous system ignore simultaneity at their peril.

Under certain conditions with microdata, chronology or competitive forces will prevent simultaneity from being empirically important in housing market analyses. Still, the simultaneity exposed here does raise some interesting questions about interpreting 
first-stage hedonic price models with transactions data. While such models cannot help but represent the true hedonic price surface faced by home buyers, might $P$ and $S$ nonetheless be simultaneously determined so that the coefficients do not represent causal effects? The hedonic price surface functions to equate the supply and demand of specific housing attributes in the local housing market (Rosen, 1974). The response of a specific attribute to changes in its own hedonic price is part of the theory, and not a problem in estimating hedonic price surfaces. However, it is also possible that investments in a structure's attributes (refurbishment, refinishing or additions) will respond to changes in the structure's overall value (or, more technically, the unexplained portion of its price). For instance, in a gentrifying neighborhood, owners might use increased assessed values to secure home equity financing for home improvements, or add features to the house so that the structure will be attractive to the incoming residents. Similar investments would not be as likely in homes located in neighborhoods suffering generalized decline in demand.

To the extent that home improvement is responding to the changes in neighborhood value (as opposed to changes in the prices of specific attributes), some of the partial correlation between the resultant improved attributes and housing values will be spurious and the characteristics of individual housing units will suffer from endogeneity bias. ${ }^{17}$ Similar arguments might hold for neighborhood-level demographic characteristics. High-status families will be wary of moving their assets into neighborhoods that are poor investments so that increases in the "status" of the neighborhood's residents will both affect and be affected by changes in neighborhood-

\footnotetext{
${ }^{17}$ Epple (1987, p. 63) shows that the price level will effect the hedonic price of an attribute under certain circumstances, for instance.
} 
level demand for the neighborhood. Ioannides (2003) discusses endogenous social effects in housing valuation in greater detail and shows (for data using owner-reported valuations) how they can significantly affect hedonic estimates. Thus, even in differences, neighborhood demographics and housing stock characteristics might be endogenous predictors of housing prices.

While it is easiest to motivate this endogeneity with unobserved neighborhood effects, the dynamic can also arise due to omitted or unobserved attributes or amenities, common shocks at scales more local than the neighborhood or even shocks to individual structures. If home-owners or developers respond to an unexplained higher value of the site by building different types of housing attributes on that site, the "hedonic prices" of those attributes will be biased and inappropriate as either the measure of the equilibrium price of the attribute or as inputs into the second stage of a hedonic demand study. Common use of home equity loans - the availability and size of which are conceivably correlated with home price appreciation - to expand or refurbish homes could exacerbate the bias, at least if credit constraints are important.

In our aggregate data, the system of equations exposes simultaneity across most neighborhood characteristics and substantially changes the price equation coefficients. Whether these same problems cause bias in first-stage hedonics using transactions data remains to be seen. It does not seem particularly controversial to suggest that the addition of an extra bedroom or bathroom, installation of hard-wood floors, cementing in of a fireplace, subdivision of a lot or structure or finishing of a basement could be undertaken with the future sales price of the home in mind, and not just the hedonic prices of the affected attributes. Unfortunately, we cannot address the empirical 
importance of such considerations here. While the difference between the partial correlation expressed by an OLS hedonic price surface and a causal effect may be of little import to a home buyer, this distinction is significant for developers, policy makers and incumbent residents deciding on investment in their existing structure’s characteristics. For them, well-identified, causal effects are the relevant effects if and when they do differ from the relatively easily observed hedonic price surface. These hedonic price effects are also a critical input into analyses of housing demand (the second stage of hedonic demand studies). These results suggest that their sensitivity to forms of misspecification besides functional form is warranted.

\section{CONCLUSION}

This paper uses a rich simultaneous equations framework to examine the effects of a major economic development policy: the federal Empowerment Zone program. Because of its generosity and design, this program offers the best chance to find positive effects of spatially targeted economic development policies. The system of equations approach adopted here recasts the neighborhood as the result of a complex interplay of forces coming from the housing market, demographic sorting and residential development. It allows for a much richer picture of neighborhood outcomes to emerge.

The results on the direct and indirect effects are striking in light of the goals and rationale of the policy. Empowerment Zones were not supposed to be property value enhancement programs. Instead, EZs were understood as attempts to improve neighborhoods across many dimensions. One would thus expect that the direct effects of Empowerment Zone interventions would be minimal, but that the indirect effects that 
they catalyze would be large. We find instead that the direct effects are large, while the indirect effects are complex and mostly offsetting. These results fit well into the existing literature on spatially targeted economic development programs.

These results suggest some interesting and perhaps troubling questions should be asked about the EZ program and other spatially targeted economic development policies. The results for poverty and education in the system of equations are consistent with the policy making neighborhoods less attractive to middle-class families, the results for density suggest a decrease in population, and the results for renters suggest a decrease in the rental housing stock. One interpretation of these results is that program monies were used to destroy low-value housing and rental properties, leaving a smaller but more expensive stock of owner occupied homes in a neighborhood catering to low-income households. Lynch and Zax (2008) suggest that the lack of employment effects is due to the capitalization of business incentives into non-residential land prices. To the extent that zoning is flexible enough to allow residentially zoned land to be transferred into nonresidential land, this increase in commercial real estate prices could push up home values. While we do not believe either of these effects could be big enough to account for the entire EZ effect in our estimates, it does suggest caution in interpreting the large increases in home values as pure benefits of the program in terms of neighborhood quality of life.

The more important contribution of the paper, however, is the presentation of a parsimonious-yet-complex system of many important economic and demographic forces that are affected by the EZ program which allows us to expose and explore the simultaneous relationships among neighborhood characteristics. The full results allow for a very rich view of the interactions among housing market, demographic and housing 
stock characteristics in U.S. metropolitan areas. It sorts out causal pathways between housing prices and neighborhood characteristics, and it lays bare the simultaneous effects of these characteristics on one another. The simultaneity raises additional concerns about the use of aggregate data to infer policy effects. The substantial changes in our policy effects as we move from our OLS models to our system of equation models suggests that - in the presence simultaneity - single-equation estimates of neighborhood-level effects with aggregate data can be in considerable error even when appropriate identification strategies are used for the variables of interest. ${ }^{18}$ Thus, besides offering evidence on the effects of an increasingly popular form of government intervention in cities, our analysis offers a better understanding of neighborhood dynamics and the rich simultaneity present in the spatial working-out of metropolitan housing markets.

\section{References}

Aaronson, D. (2001). "Neighborhood Dynamics." Journal of Urban Economics 49(1): 131.

Bartik, Timothy J. (1991). "Who Benefits from State and Local Economic Development Policies?” Kalamazoo, MI: Upjohn Institute.

Boarnet, Marlon G. (2001). "Enterprise Zones and Job Creation: Linking Evaluation and Practice.” Economic Development Quarterly, 15(3): 245-254.

Boarnet, Marlon G. and William Bogart (1996). “Enterprise Zones and Employment: Evidence from New Jersey.” Journal of Urban Economics, 40(2): 198-215.

Bond, Eric W. and N. Edward Coulson (1989). "Externalities, Filtering and neighborhood change.” Journal of Urban Economics, 26: 231-249.

\footnotetext{
${ }^{18}$ Greenstone and Gallagher (2008) acknowledge - but do not address - this possibility in their analysis of hazardous waste sites.
} 
Bondonio, Daniele and John B. Engberg (2000). "Enterprise Zones and Local Employment: Evidence from the States' Programs.” Regional Science and Urban Economics, 30(5): 519-549.

Bondonio, Daniele and Robert T. Greenbaum (2007). "Do local tax incentives affect economic growth? What mean impacts miss in the analysis of enterprise zones policies.” Regional Science and Urban Economics 37(1): 121-136.

Brueckner, Jan K. (1980). "Residential succession and land-use dynamics in a vintage model of urban housing." Regional Science and Urban Economics. 10: 225-240.

Brueckner, Jan K. and Stuart S. Rosenthal (forthcoming). "Gentrification and Neighborhood Cycles: Will America's Future Downtowns be Rich?" Forthcoming in Review of Economics and Statistics.

Busso, Matias and Patrick Kline (2008). "Do local economic development programs work? Evidence from the federal Empowerment Zone program.” Cowles Foundation Discussion Paper No. 1638, Yale Economics Department Working Paper No. 36. Available at SSRN: http://ssrn.com/abstract= 1090838

Card, D., E., A. Mas and J. Rothstein (2007) "Tipping and the Dynamics of Segregation" (April 2007). NBER Working Paper No. W13052. Available at SSRN: http://ssrn.com/abstract=986902

Elvery, Joel A. (2009). "The impact of enterprise zones on resident employment: an evaluation of enterprise zone programs of California and Florida.” Economic Development Quarterly 23(1), 44-59.

Engberg, John B. and Robert T. Greenbaum (1999). "State Enterprise Zones and Housing Markets.” Journal of Housing Research, 10(2): 163-187.

Epple, Dennis (1987). "Hedonic prices and implicit markets: estimating demand and supply functions for differentiated products.” Journal of Political Economy, 95(1): 59-80.

Erickson, Rodney and Susan Friedman (1990). "Enterprise Zones 2: A Comparative Analysis of Zone Performance and State Government Policies.” Environment and Planning C: Government and Policy, 8(4): 363-378.

Freeman, A. Myrick III, (1979) "The Hedonic Price Approach to Measuring Demand for Neighborhood Characteristics," in Segal, David, ed. The Economics of Neighborhood (New York, Academic Press), pp. 191-217.

Galster, George, J. Cutsinger and U. Lim. (2007) “Are Neighborhoods self-stabilising? Exploring endogenous dynamics.” Urban Studies 44(1): 167-186. 
Greenbaum, Robert T. (1998). An Evaluation of State Enterprise Zone Policies: Measuring the Impact on Business Decisions and Housing Market Outcomes. unpublished PhD. Thesis, H. John Heinz III School of Public Policy and Management. Pittsburgh: Carnegie Mellon University.

Greenbaum, Robert T. and Daniele Bondonio (2004). "Losing Focus: A Comparative Evaluation of Spatially Targeted Economic Revitalization Programmes in the US and the EU.” Regional Studies, 38(3): 319-334.

Greenbaum, Robert T. and John B. Engberg (2000). "An Evaluation of State Enterprise Zone Policies.” Policy Studies Review 17(2/3): 29-46.

Greenstone, Michael and Justin Gallagher (2008). "Does Hazardous Waste Matter: Evidence from the Housing Market and the Superfund Program." Quarterly Journal of Economics, 123(3): 951-1003.

Hanson, Andrew (2008). "Poverty reduction and local employment effects of geographically-targeted tax incentives and grants: an instrumental variables approach.” Urban and Regional Analysis Group Working Paper No. 08-10, Georgia State University, Andrew Young School of Policy Studies.

Ionnides, Yannis M. (2003). “Interactive property valuations.” Journal of Urban Economics, 53: 145-170.

Kain, John (1968). "Housing Segregation, Negro Employment and Metropolitan Decentralization.” Quarterly Journal of Economics, 82: 175-197.

Krupka, Douglas J. and Douglas S. Noonan (2009). "Empowerment Zones, neighborhood change and owner-occupied housing." Regional Sciecne and Urban Economics, 34(4): 386-396.

Landers, Jim (2006). "Why don’t enterprise zones work? Estimate of the extent that EZ bnefits are capitalized into property values." Journal of Regional Analysis and Policy, 36(1): 15-30.

Lynch, Devon and Jeffrey S. Zax (2008). "Incidence and substitution in Enterprise Zone Programs: The case of Colorado.” Unpublished working paper available at http://www.colorado.edu/Economics/Zax/workingpapers/LynchandZax.pdf .

McCarthy, John (1998). “US Urban Empowerment Zones.” Land Use Policy, 15(4): 319-330.

National Atlas of the United States (2004) Cities and Towns of the United States, National Atlas of the United States, Reston, VA. Last accessed online on 10 August 2005 at: http://nationalatlas.gov/atlasftp.html 
Nelson, Jon P. (1979) “Airport Noise, Location Rent, and the Market for Residential Amenities," Journal of Environmental Economics and Management, vol. 6, pp. 320331.

Noonan, Douglas S., Douglas J. Krupka and Brett M.Baden (2007). "Neighborhood Dynamics and Price Effects of Superfund Site Clean-up." Journal of Regional Science 47(4): 665-692.

Oakley, Deirdre and Hui-shien Tsao (2006). "A new way of revitalizing distressed urban communities? Assessing the impact of the federal empowerment zone program." Journal of Urban Affairs 25(5): 443-471.

Oakley, Deirdre and Hui-shien Tsao (2007a). "Socioeconomic gains and spillover effects of geographically targeted initiatives to combat distress: An examination of Chicago's Empowerment Zone.” Cities 24(1):43-59.

Oakley, Deirdre and Hui-shien Tsao (2007b). “The Bottom-Up Mandate: Fostering Community Partnerships and Combating Economic Distress in Chicago's Empowerment Zone.” Urban Studies 44(4): 819-843.

O’Byrne, Patricia Habuda, Jon P. Nelson, and Joseph J. Seneca, (1985) “Housing Values, Census Estimates, and the Environmental Cost of Airport Noise: A Case Study of Atlanta," Journal of Environmental Economics and Management, vol. 12, no. 2, pp. 169-178.

Papke, Leslie (1993). "What Do We Know about Enterprise Zones.” In Poterba, James, ed. Tax Policy and the Economy. Cambridge: National Bureau of Economic Research and MIT Press, pp. 37-72.

Papke, Leslie (1994). “Tax Policy and Urban Development: Evidence from the Indiana Enterprise Zone Program.” Journal of Public Economics 54(1): 37-49.

Peters, Alan H. and Peter S. Fisher (2002). "State Enterprise Zone Programs: Have they Worked?” Kalamazoo, MI: Upjohn Institute.

Rosen, Sherwin (1974). "Hedonic Prices and Implicit Markets: Product differentiation in pure competition.” The Journal of Political Economy, 82(1): 34-55.

Rosenthal, Stuart S. (2008). "Old Homes, Externalities, and Poor Neighborhoods: A Model of Urban Decline and Renewal" Journal of Urban Economics 63(3): 816-840.

Schelling, T. C. (1969). "Models of Segregation." The American Economic Review 59(2): 488-493.

Schelling, T. C. (1971). "Dynamic Models of Segregation." Journal of Mathematical Sociology 1(2): 143-186. 
Wallace, Marc A. (2003). "An Analysis of Presidential Preference in the Distribution of Empowerment Zones and Enterprise Communities.” Public Administration Review 63(5): 562-572.

Wallace, Marc A. (2004). "Congressional considerations and urban characteristics in the selection of empowerment zones and enterprise communities." Journal of Urban Affairs, 26(5), 593-609.

Winnick, L. (1966). "Place Prosperity vs. People Prosperity: Welfare Considerations in the Geographic Redistribution of Economic Activity,” in Real Estate Research Program, University of California at Los Angeles, Essays in Honor of the Sixty-fifth Birthday of Leo Grebler. Los Angeles, CA: Real Estate Research Program, pp. 273283. 
Table 2: OLS (first difference) regressions of $\ln (\mathrm{Md} . \mathrm{Val})$

\begin{tabular}{|c|c|c|c|c|c|c|c|c|}
\hline & $\begin{array}{l}2.1 \\
\text { coef }\end{array}$ & $\mathrm{t}$ & $\begin{array}{l}2.2 \\
\text { coef }\end{array}$ & $\mathrm{t}$ & $\begin{array}{l}2.3 \\
\text { coef }\end{array}$ & $\mathrm{t}$ & $\begin{array}{c}2.4 \\
\text { coef }\end{array}$ & \\
\hline$E Z 1$ & 0.2392 & 9.35 & 0.2221 & 8.52 & 0.4385 & 9.18 & 0.4205 & 8.73 \\
\hline$E Z 2$ & 0.0386 & 1.86 & 0.0221 & 1.04 & & & & \\
\hline EZever & -0.0184 & -1.22 & -0.0045 & -0.29 & & & & \\
\hline Workers & 0.0220 & 1.52 & & & 0.0236 & 1.78 & & \\
\hline Poverty & -0.1613 & -13.33 & & & -0.1607 & -13.43 & & \\
\hline Children & -0.0367 & -2.18 & & & -0.0408 & -2.42 & & \\
\hline College & 0.4088 & 31.76 & & & 0.4091 & 32.67 & & \\
\hline Density & $2.06 \times 10^{-6}$ & 2.80 & & & $2.69 \times 10^{-6}$ & 3.19 & & \\
\hline Rooms & 0.0937 & 34.81 & & & 0.0952 & 35.58 & & \\
\hline Renters & 0.0811 & 5.57 & & & 0.0776 & 5.34 & & \\
\hline New Units & 0.1795 & 33.12 & & & 0.1793 & 33.27 & & \\
\hline Muni.HoHos & -0.0526 & -7.19 & -0.0435 & -5.57 & -0.0428 & -5.84 & -0.0339 & -4.36 \\
\hline Muni.Vals & 0.5380 & 43.28 & 0.5741 & 45.42 & 0.5338 & 42.30 & 0.5703 & 44.41 \\
\hline Muni.Inc & 0.0619 & 4.00 & 0.1813 & 11.40 & 0.0572 & 3.74 & 0.1760 & 11.18 \\
\hline Dist.PPExp & 0.0027 & 0.62 & 0.0109 & 2.40 & 0.0035 & 0.82 & 0.0124 & 2.72 \\
\hline R-sq & 0.1597 & & 0.0780 & & 0.1625 & & 0.0792 & \\
\hline obs & 107413 & & 108068 & & 106769 & & 106782 & \\
\hline
\end{tabular}

Note: All regressions include MSA dummies, MSA-specific rent gradients and county amenity score. 
Table 3: 3SLS estimation using control-group identification strategy.

\begin{tabular}{|c|c|c|c|c|c|c|c|c|c|c|}
\hline & & \multicolumn{9}{|c|}{ Equation (Dependent Variable) } \\
\hline & & $\ln (\mathrm{Md} \cdot \mathrm{Val}) \mathrm{a}$ & Workers & Poverty & Children & College & Density & Rooms & Renters & New Units \\
\hline \multirow{25}{*}{ 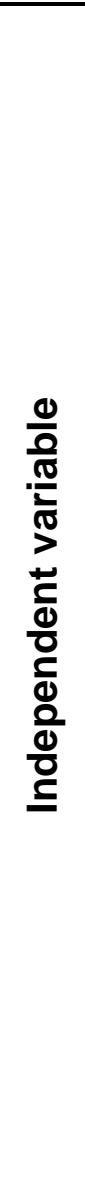 } & \multirow[t]{2}{*}{$E Z 1$} & 0.1963 & -0.0110 & 0.0170 & 0.0122 & -0.0291 & -752.63 & 0.0818 & -0.0239 & -0.0032 \\
\hline & & 10.92 & -1.42 & 2.66 & 2.91 & -4.05 & -4.95 & 2.08 & -3.31 & -0.16 \\
\hline & \multirow[t]{2}{*}{$E Z 2$} & 0.0435 & -0.0069 & 0.0067 & 0.0114 & -0.0130 & -693.81 & 0.0632 & -0.0213 & -0.0030 \\
\hline & & 2.46 & -0.95 & 1.12 & 2.96 & -1.95 & -4.94 & 1.73 & -3.18 & -0.16 \\
\hline & \multirow[t]{2}{*}{ EZever } & -0.0551 & 0.0068 & -0.0012 & -0.0027 & 0.0052 & 89.15 & 0.0047 & 0.0018 & 0.0105 \\
\hline & & -4.00 & 1.22 & -0.25 & -0.89 & 1.01 & 0.81 & 0.17 & 0.34 & 0.74 \\
\hline & \multirow[t]{2}{*}{ In(Md.Val) } & 0.1614 & 0.1457 & 0.0011 & -0.0400 & 0.1702 & 574.69 & 0.3954 & -0.0406 & 0.2688 \\
\hline & & 15.74 & 13.06 & 0.13 & -6.31 & 16.21 & 2.50 & 6.86 & -3.67 & 9.45 \\
\hline & \multirow[t]{2}{*}{ Workers } & 0.4166 & 0.0375 & -0.5471 & 0.3263 & -0.5771 & 3244.38 & -4.0711 & 0.3383 & -2.3983 \\
\hline & & 4.71 & 3.69 & -30.77 & 23.18 & -23.98 & 5.99 & -37.29 & 13.27 & -46.28 \\
\hline & \multirow[t]{2}{*}{ Poverty } & -1.1228 & -1.2093 & 0.0121 & 0.3776 & -0.6345 & 13792.14 & -6.5324 & 0.6753 & -3.6083 \\
\hline & & -9.65 & -42.90 & 1.39 & 22.16 & -18.07 & 20.60 & -45.79 & 19.81 & -55.29 \\
\hline & \multirow[t]{2}{*}{ Children } & 1.0082 & 1.8682 & 1.1119 & 0.0105 & 1.0130 & 7023.89 & 6.1152 & -0.1035 & 4.8429 \\
\hline & & 4.79 & 37.50 & 25.77 & 1.26 & 17.15 & 6.52 & 21.25 & -1.90 & 40.32 \\
\hline & \multirow[t]{2}{*}{ College } & 0.2064 & -0.5605 & -0.2122 & 0.2251 & 0.6064 & -1331.16 & -1.9052 & 0.0765 & -1.2269 \\
\hline & & 2.95 & -33.43 & -12.23 & 23.60 & 31.70 & -3.33 & -19.13 & 3.98 & -25.73 \\
\hline & \multirow[t]{2}{*}{ Density } & $1.75^{\star} 10^{-5}$ & $5.72 * 10^{-6}$ & $1.70 * 10^{-5}$ & $9.78 * 10^{-6}$ & $-4.48^{*} 10^{-6}$ & $8.24 * 10^{-2}$ & $1.48 * 10^{-4}$ & $-3.06^{\star} 10^{-5}$ & $4.46 * 10^{-5}$ \\
\hline & & 3.54 & 3.67 & 14.39 & 12.55 & -3.00 & 5.68 & 21.85 & -24.14 & 11.86 \\
\hline & \multirow[t]{2}{*}{ Rooms } & 0.0012 & -0.1667 & -0.1194 & 0.0339 & -0.1098 & 2323.34 & 0.0239 & 0.1169 & -0.4611 \\
\hline & & 0.06 & -35.04 & -28.36 & 10.12 & -19.90 & 22.33 & 3.81 & 25.33 & -38.64 \\
\hline & \multirow[t]{2}{*}{ Renters } & -0.4430 & 0.4926 & 0.5329 & 0.0700 & 0.1357 & -19969.50 & 4.7556 & 0.0440 & 1.8285 \\
\hline & & -2.86 & 11.03 & 14.26 & 2.89 & 3.09 & -27.78 & 24.91 & $\begin{array}{r}4.79 \\
\end{array}$ & 16.81 \\
\hline & \multirow[t]{2}{*}{ New Units } & -0.0128 & -0.3083 & -0.2275 & 0.1186 & -0.1534 & 2727.61 & -1.4732 & 0.1589 & 0.0421 \\
\hline & & -0.60 & -54.50 & -51.52 & 36.29 & -21.96 & 17.53 & -50.02 & 23.63 & 7.48 \\
\hline & Muni.HoHos & -0.0099 & 0.0122 & -0.0030 & -0.0139 & 0.0172 & 600.44 & -0.0197 & 0.0167 & 0.0065 \\
\hline
\end{tabular}




\begin{tabular}{|l|rrrrrrrrr} 
& -0.99 & 2.97 & -0.86 & -6.43 & 4.49 & 7.61 & -0.97 & 4.41 & 0.63 \\
Muni.Vals & 0.5708 & -0.0594 & 0.0089 & 0.0159 & -0.0678 & -467.03 & -0.1297 & 0.0132 & -0.0920 \\
& 50.72 & -7.94 & 1.47 & 3.85 & -9.70 & -3.13 & -3.40 & 1.83 & -4.80 \\
Muni.Inc & -0.1016 & 0.0610 & 0.0374 & -0.0068 & 0.0511 & -977.79 & 0.4082 & -0.0667 & 0.1680 \\
& -4.91 & 7.46 & 5.45 & -1.51 & 6.57 & -6.04 & 10.06 & -8.80 & 8.09 \\
Dist.PPExp & 0.0102 & 0.0097 & 0.0075 & -0.0040 & 0.0072 & -85.75 & 0.0465 & -0.0046 & 0.0326 \\
& 1.89 & 4.23 & 3.95 & -3.29 & 3.41 & -1.90 & 4.02 & -2.14 \\
\hline
\end{tabular}

Note: All equation include metropolitan fixed effects. Price equation also includes county-level amenity score and the interaction between a metropolitan dummy and the block groups distance to the nearest place center. 
Table 4: 3SLS estimation using auxiliary regression identification strategy

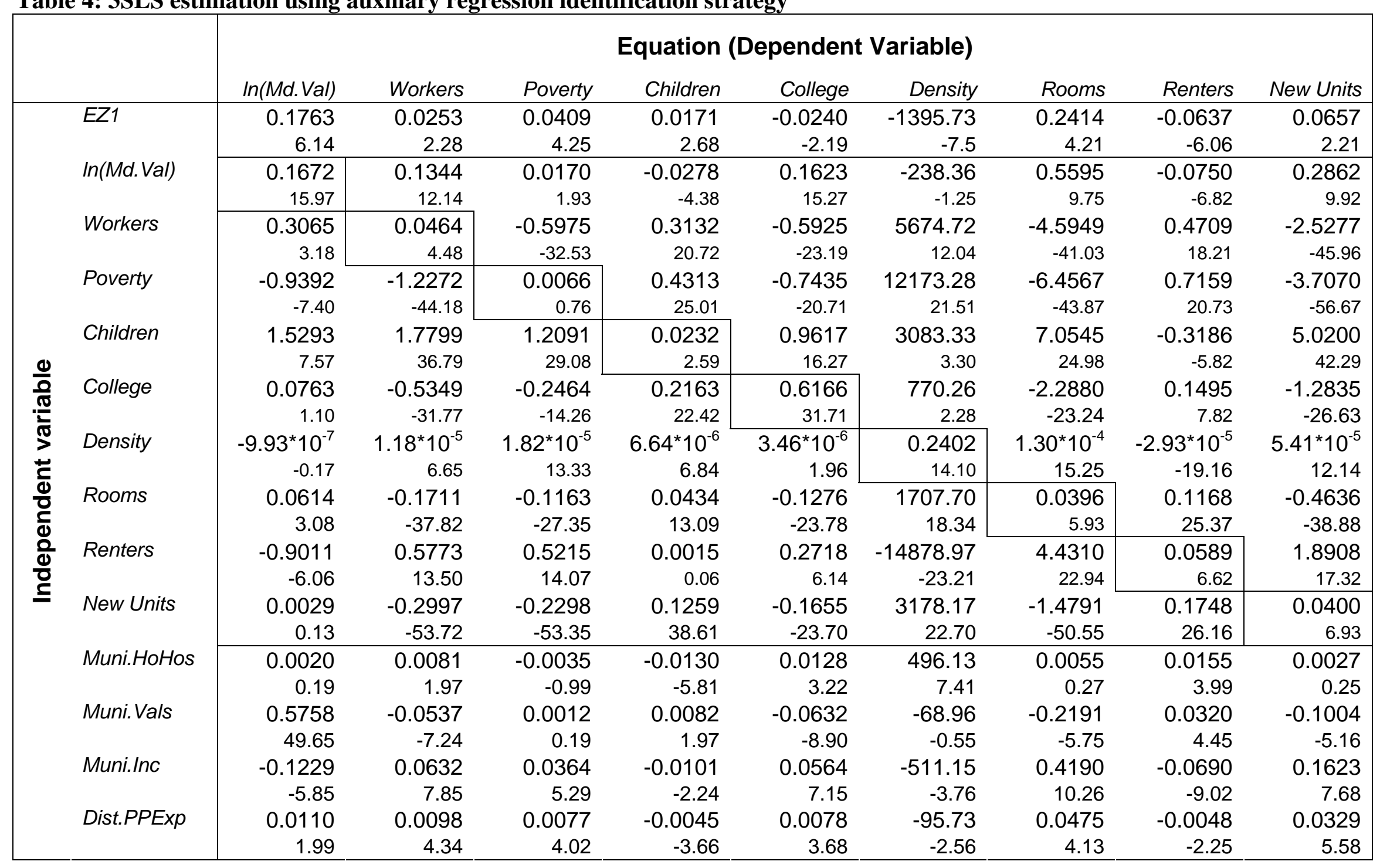


Note: All equation include metropolitan fixed effects. Price equation also includes county-level amenity score and the interaction between a metropolitan dummy and the block groups distance to the nearest place center. 